\title{
El Mediador en las primeras obras de M. Blondel. Para una superación del extrinsecismo
}

\author{
César Izquierdo \\ FACULTAD DE TEOLOGÍA \\ UNIVERSIDAD DE NAVARRA. PAMPLONA. ESPAÑA \\ cizquier@unav.es
}

Resumen: La superación del extrinsecismo es una tarea urgente para defender la racionalidad de la teología. El pensamiento de M. Blondel (18611949) tal como aparece en sus primeras obras ofrece elementos capaces de sustentar esa superación. En el artículo se examinan los diferentes niveles que sigue su filosofía: la dialéctica de la acción, la mediación de la acción, lo sobrenatural inmanente, el Mediador. A partir del Mediador, es posible una consideración del misterio cristiano ajena a toda separación que impida la consistencia racional de la teología.

Palabras clave: Mediador, mediación, extrinsecismo, sobrenatural

Abstract: Overcoming extrinsecism is an urgent task in the defense of the rationality of theology. M. Blondel's (1861-1949) thought, as it appears in his early works, provides elements capable of sustaining this improvement. This paper examines the different levels in Blondelian philosophy of action's process of achieving unity in knowledge and reality: the dialectic of action, the mediation of action, the immanent and anonymous supernatural, and the Mediator. Taking the Mediator as a starting point, it is possible to avoid all kinds of separation that harm theology's rational consistency while considering the Christian mystery.

Key words: Mediator, mediation, extrinsecism, supernatural 
INTRODUCCIÓN: EL “EXTRINSECISMO”

El "extrinsecismo" es un neologismo utilizado por Maurice Blondel en su obra Histoire et Dogme (1904) para indicar la interpretación dogmática de los hechos históricos del Nuevo Testamento, es decir, la realizada con criterios teológicos, sin reconocer una competencia propia al método histórico propiamente dicho. Según Blondel, el «extrinsecismo» establece que en la relación de los hechos históricos con las creencias, estas son determinantes. "Extrínseca la relación del signo con la cosa significada, extrínseca la relación de los hechos con la dogmática que les está superpuesta, extrínseca la unión de nuestro pensamiento y de nuestra vida con las verdades que se le proponen desde afuera"'. Para el extrinsecismo el papel de los hechos consiste en servir meramente de signos de lo sobrenatural y divino a través de su carácter milagroso o sobrenatural. Una vez presentado el hecho, un sencillo razonamiento va desgajando de él su significación divina: el hecho es milagroso, solo Dios puede haber hecho este milagro, luego Dios garantiza con su omnipotencia esta o aquella otra verdad. En este caso, afirma Blondel, «los hechos históricos no son más que un vehículo cuyo interés se limita al uso apologético que se puede hacer de ellos» ${ }^{2}$. En consecuencia, la realidad concreta de los hechos históricos carece de valor. Los hechos están aquí al servicio de los dogmas, pero sin proporcionar al dogma ningún elemento que afecte intrínsecamente a su contenido. Los hechos pueden acercarse más o menos a la fe pero sin penetrar dentro de ella. Así pues, el extrinsecismo no es sino el resultado de la incapacidad de integrar lo histórico y lo dogmático.

Por el lado opuesto al extrinsecismo estaba el "historicismo", término con el que Blondel designaba, en Historia y Dogma, el modo de proceder de A. Loisy. Blondel señalaba que Loisy era igualmente incapaz de integrar los hechos con las creencias, pero ahora los hechos históricos críticamente conocidos eran determinantes, lo cual llevaba a una oposición entre lo que afirma la historia y lo que pertenece al credo de la Iglesia.

1 M. Blondel, Histoire et Dogme, en M. Blondel, Oeuvres complètes, II: 1888-1913. La philosophie de l'action et la crise moderniste (PUF, Paris 1997) 397: "Extrinsèque la relation du signe avec la chose signifiée, extrinsèque le rapport des faits avec la dogmatique qui y est superposée, extrinsèque la liaison de notre pensée et de notre vie avec les vérités qu'on lui propose du dehors».Ver la edición española: M. BLONDEL, Historia y Dogma, Estudio introductorio y edición de C. Izquierdo (Cristiandad, Madrid 2004) 90.

2 M. Blondel, Histoire et Dogme, 395 (ed. esp., 88). 
La dificultad de integrar lo histórico y lo dogmático era, y sigue siendo, un ejemplo entre muchos de un reto implicado en la misma esencia del misterio cristiano. Pensemos en realidades como la gracia y la naturaleza o la libertad, lo natural y lo sobrenatural, la historia y la fe, la Iglesia como institución y la Iglesia como misterio, la moral natural y la evangélica, el Dios Uno y el Dios Trino, la naturaleza humana y la naturaleza divina en Cristo, la omnipotencia divina y la cruz, la Iglesia y el individuo creyente, los sacramentos y el mundo, etc.; todos ellos presentan el desafío de mantener la plena e íntegra realidad de los dos elementos -humano y divino- sin comprometer de ninguna manera la unidad. Dicho en otras palabras: el desafío que se presenta es el de evitar tanto el extrinsecismo como la naturalización de realidades divinas reveladas.

La gran cuestión que está en la base de todas las alternativas que se acaban de apuntar es el misterio central de la fe cristiana, en el que lo humano y lo divino se dan en una plenitud única: la encarnación del Verbo, el misterio de Jesús el Cristo. Cuando afirmamos "Jesús es Señor" estamos confesando que a un hombre -Jesús- le pertenece no solo la condición humana, sino también la divina. Con palabras que se remontan al concilio de Calcedonia (451), "theós alethinós kai ánthropos alethinós": Jesucristo es verdadero Dios y verdadero hombre.

La conjunción copulativa " $y$ " sirve ordinariamente para unir, para explicitar la continuidad en las propiedades de un ser o de una acción. Decimos de alguien que es, por ejemplo, "inteligente $y$ habilidoso"; de un alimento que es "ligero $y$ nutritivo" o que tal persona "sabe hablar $y$ escuchar". En cambio, en el caso de Cristo, Dios y hombre, la conjunción "y" ("kai") expresa la unión de lo que por sí mismo es contrario. Por definición, Dios no es hombre, ni el hombre es Dios. Entre Dios y el hombre existe, de hecho, una contraposición metafísica que deriva de la relación creatural, la que une a la criatura con su Creador. Por esa razón, al afirmar la fe en Cristo verdadero Dios y verdadero hombre, la conjunción " $y$ " no indica continuidad sino tensión, porque a lo que de suyo sería disyunción o incluso negatividad (hombre, y por tanto no-Dios; Dios, y por tanto no-hombre) los pone juntos y los atribuye a una persona, y al hacerlo establece una fortísima tensión conceptual que supone un auténtico desafío para la racionalidad humana. Precisamente esa racionalidad tratará de superar la tensión interpretando la unidad y la dualidad de Cristo de manera racionalmente aceptable, es decir, debilitando a la una o a la otra en favor de la contraria, o sometiendo todo a un proceso evolutivo en el que sea posible el despliegue sucesivo de los opuestos. Al actuar de ese modo, nos encontramos con la ten- 
dencia a evitar toda tensión, a la transparencia que no exige decisión ni compromiso. Y así, por ejemplo, se habla del Jesús de la historia y del Cristo de la fe, entendidos no solo como dos niveles del conocimiento, distinguibles desde un punto de vista metodológico, sino también en la realidad, aceptables a la vez aunque de hecho se contradigan, porque se los considera situados en planos distintos.

La tensión conceptual que se da en cristología se extiende a otros misterios cristianos -como los apuntados anteriormente- en los que lo humano y lo divino aparecen de modo semejante -en realidad, derivado- de la cristología: la naturaleza y la gracia, lo natural y lo sobrenatural, etc. De hecho, buena parte de las herejías históricas responden a intentos de solventar el problema de la unidad entre lo humano y lo divino con soluciones en las que una u otra realidad se ve afectada. Por ejemplo, ¿qué es el pelagianismo sino una propuesta simple de relacionar sin problemas la naturaleza y la gracia?; o ¿qué es el protestantismo eclesial sino una manera de superar las antinomias que Lutero encontraba entre la Iglesia de santos y la de los pecadores? Son algunos ejemplos que se podrían prolongar a otras áreas de la fe y de la praxis cristiana. El problema es que esas soluciones solo sirven si se anula uno de los polos: el divino (la gracia) en el caso del pelagianismo; el humano (la institución eclesial) en el luteranismo. La otra posibilidad es la que podría llamarse "integrista" porque admite la integridad, pero no la integración de ambas dimensiones. La primera posibilidad -la anulación efectiva de lo humano o de lo divino- es rechazada por la Iglesia como herética; la segunda -como ya se ha dicho- no es rechazada de la misma manera porque es formalmente correcta y no pone en juego, como la anterior, la fe; pero al mismo tiempo plantea un problema de gran envergadura a la reflexión creyente: el problema del extrinsecismo, causa de esterilidad y de descrédito de la teología, que necesita ser superado.

La consecuencia es -como ya se ha apuntado- la instauración de una dualidad que con frecuencia es alternativa y que da lugar a dos formas opuestas de extrinsecismo: la que impone a la fuerza y desde fuera la unión (integrismo) y la que admite pacíficamente la separación, dando así lugar a diversas manifestaciones de fideísmo. Se impone en consecuencia la superación del extrinsecismo y la única vía para ello es una comprensión cristológica en la que la naturaleza divina y la naturaleza humana se comprendan en la unidad mutua y en la integridad de cada una de ellas. 
Aunque la raíz del extrinsecismo se halla, en último término, en la cristología insuficiente que está en la base, su manifestación más clara aparece probablemente en la antropología, y concretamente en la explicación del modo como se relacionan la naturaleza y la gracia, lo natural y lo sobrenatural. Tras la superación del optimismo antropológico, que cree no necesitar la gracia (pelagianismo) y del pesimismo que solo a la gracia concede valor (protestantismo), la teología católica se enfrentó con la necesidad de respetar los "órdenes" sin mezclarlos, y al mismo tiempo lograr la unidad de la existencia cristiana. Era este un desafío no fácil de resolver y, de hecho, durante mucho tiempo la teología no logró superar formas más o menos claras de extrinsecismo al presentar a la gracia como un don superpuesto a una naturaleza humana completa en sí misma.

La superación del extrinsecismo en sus diversas manifestaciones se logrará a partir de una cristología en la que converjan, en plenitud de unidad, tanto la teología como la economía de las que hablaban los Padres; tanto la dimensión descendente como la ascendente del misterio cristiano. El punto de encuentro es una cristología del Mediador, Cristo Jesús (cfr. 1 Tim 2, 5).

La teología del Mediador ha sido objeto de estudios patrísticos e históricos ${ }^{3}$, aunque no está todavía suficientemente desarrollada en un discurso propiamente teológico. Estudios recientes han puesto de relieve el significado que el Mediador y la mediación tienen, por ejemplo, en

\footnotetext{
Algunos ejemplos: G. RémY, Le Christ Mediateur dans l'oeuvre de Saint Augustin, 2 vols. (Atelier Reproduction des Theses Universite Lille III, Lille 1979); A. Vanhoye, Gesù Cristo il mediatore nella lettera agli ebrei (Cittadella, Assisi 2007); P. Ciarlantini, "La mediación de Cristo en la Patrística", en Revista Agustiniana 23 (1982) 325-379; C. M. BANDioli, Cristo unico mediatore e le formule della mediazione (Edizioni Studio Domenicano, Bologna 2002); C. M. BANDioli, "Cristo Mediatore nell'Adversus haereses di Sant'Ireneo", en Divus Thomas 105 (2002) 203-224; C. IzQuIERdo, "Mediatoris sacramentum. Cristo mediador, en san Agustín”, en Scripta Theologica 39 (2007) 735-763; G. GuITIÁN, La mediación salvífica según Santo Tomás de Aquino (Eunsa, Pamplona 2004); C. IzQuierdo, "Cristo "mediador". Perspectiva bíblica", en Scripta Theologica 40 (2008) 695-732; P. O'Callaghan, "La mediación de Cristo en su Pasión”, en Scripta Theologica 18 (1986) 771-798; D. R. DeLACEY, "Jesus as mediator", en Journal for the study of the New Testament 29 (1987) 101-121.
} 
la teología de Henri de Lubac ${ }^{4}$. En este trabajo vamos a examinar el planteamiento que Maurice Blondel -de quien H. de Lubac y otros han recibido inspiración e influjo- hace del Mediador especialmente en L'Action (1893), pero también en las otras dos obras más significativas del periodo apologético: Lettre sur l'apologétique (1896) e Histoire et Dogme (1904). Con su explicación del Mediador, es como, en último término, Blondel permite salir "de esa pesadilla, comúnmente llamada extrinsecismo" ". Años más tarde, lo que Blondel dice en estas obras sobre el Mediador será "desarrollado en la Tetralogía"6. Pero este desarrollo posterior queda fuera de nuestra consideración. Antes de llegar al Mediador es preciso mostrar la medición en la misma acción, punto de partida y motor de la filosofía blondeliana.

\section{LA FILOSOFÍA BLONDELIANA DE LA ACCIÓN}

La pregunta con la que comienza la primera gran obra de Blondel, $\mathrm{La}$ acción, pone ante los ojos que el objetivo del filósofo de Aix en Provence es plenamente moderno, ya que no es otro que el sentido de la vida: "¿Sí o no? ¿Tiene la vida humana un sentido y el hombre un destino?” sentido de la vida que ahí se nombra, en todo caso, no se debe interpretar en clave psicológica, sino que tiene que ver con lo que él mismo llama "el problema humano". Este problema humano es el verdadero objeto de la filosofía, la cual no puede perder nunca de vista lo que constituye el centro y el núcleo de la vida del hombre.

La separación entre ciencia y moral, entre inteligencia y voluntad que ya se encontraba en Descartes, acabó fraguando en la filosofía kantiana. "Lo que sobre todo me proponía era la refutación de Kant y de Rénan",

4 Cfr. la tesis doctoral de A. Persidor, Cristología y antropología en Henri de Lubac. Mediación y Cristo mediador (Facultad de Teología. Universidad de Navarra, Pamplona 2016), pro manuscripto, de próxima publicación. Del mismo autor, "Primacía del Mediador. Hombre y Cristo en la teología de Henri de Lubac", en Scripta Theologica 48 (2016)

5 A. Marananche, Les raisons de l'espérance (Fayard, Paris 1979) 26

6 P. Favraux, Une philosophie du Médiateur: Maurice Blondel (Lethielleux-Presses Universitaires de Namur, Paris-Namur 1987) 238

7 M. Blondel, L'Action (Alcan, Paris, 1893); ed. española con introducción, versión y notas de J.M. Isasi y C. Izquierdo: La acción (BAC, Madrid 1996). Citamos con la sigla A seguida del número de página de la edición española y, entre paréntesis, el de la edición francesa: 3 (VII). 
escribió Blondel a Mourret ${ }^{8}$. Desde I. Kant, el problema humano venía representado por la relación del hombre con el saber, con el deber y con el destino. En la Crítica de la razón pura Kant resume las preguntas esenciales a las que debe responder la filosofía, y que son las conocidas: ¿qué puedo saber?; ¿qué debo hacer?; ¿qué me es posible esperar? A estas preguntas, añade en la Lógica otra que las resume a todas: ¿qué es el hombre? De esta manera quedaba formulado el carácter problemático de la concepción filosófica del hombre que se abre necesariamente a uno o a otro aspecto del ser humano, pero que es incapaz de abarcarlos a todos en unidad porque entre el saber, el deber y el esperar no hay, en realidad, auténtica comunicación. Al ser incapaz el hombre de integrar lo que sabe, lo que hace y lo que espera, quedaba preparado el campo para que surgieran las nuevas antropologías ya decididamente fragmentarias. El hombre es conocimiento (positivismo); o libertad (Schopenhauer, Nietzsche); o resultado de la historia (Marx); o fondo inconsciente (Freud).

Las preguntas de Blondel por el sentido y el destino de la vida introducen una variante significativa sobre la cuestión dejada por Kant. Ahora la pregunta no es ya por la parte (saber, deber, esperar) sino por el todo, por la posibilidad de síntesis: el sentido, el destino de toda la vida, del conjunto, del ser humano. No consiste, por tanto, en saber qué y cómo puedo conocer, o qué debo hacer, o qué es el ser, sino en lograr la unión entre ellos. Por eso, la afirmación de que el objeto de la filosofía es el problema humano, hay que entenderlo, ciertamente, sobre el trasfondo kantiano, pero con otra clave: el problema humano que constituye el verdadero objeto de la filosofía, es el de la relación entre pensar, querer y $\operatorname{ser}^{9}$. En consecuencia, si hay una respuesta a ese problema incluirá necesariamente una u otra forma de mediación entre esos actos.

El elemento radical y común a todo lo que el hombre conoce, quiere y realiza, y que constituye el punto de partida de toda investigación ulterior es, según Blondel, la acción. La acción es el elemento primero e irreductible de la vida del hombre, a partir del cual todo lo humano se

8 R. Marlé (ed.), Au coeur de la crise moderniste (Aubier, Paris, 1960) 293. Cfr. la crítica al kantismo en La acción: A 505-507 (452-454). Una de las conclusiones de Blondel es la siguiente: "Aunque tenga razón en lo que niega, el criticismo se equivoca en lo que afirma".

9 A 5 (IX) 
desarrolla. La acción es el más general y el más constante de los hechos en la vida, afirma el filósofo de $\mathrm{Aix}^{10}$. Al presentar a la acción como la realidad y la experiencia humana fundamental, a partir de la cual, como de un germen, se desarrolla todo lo demás, Blondel propone un cambio en el proceder de la investigación filosófica: anterior al "cogito" cartesiano y al acto de voluntad de Shopenhauer está la acción, el "yo actúo" blondeliano.

La acción tal como la presenta Blondel en su primera investigación tiene un sentido distinto del que le atribuía Aristóteles o del que le atribuye la filosofía analítica moderna en la que la acción se entiende a partir y en relación con el lenguaje como acto lingüístico. En realidad, el filósofo de Aix ha considerado imposible ofrecer una definición, ya que -arguye- las definiciones expresan las ideas de las cosas, y la acción es distinta de la idea de la acción. Por ese motivo no es tarea fácil definir el significado que Blondel atribuye a la acción. Deja claro, en todo caso, que la realidad de la acción solo puede ser captada de una manera propia, con la práctica.

"La acción es la síntesis del conocer, del querer y del ser, el vínculo del compuesto humano, que no se puede escindir sin destruir todo lo que se ha escindido. Es el punto preciso donde convergen el mundo del pensamiento, el mundo moral y el mundo de la ciencia. Si no se unieran en la acción, todo estaría perdido. Si pensar, si querer no es ser; si ser no es ni querer ni pensar, ¿qué es entonces esta pesadilla? Así pues, toda doctrina para la que la metafísica, la ciencia y la moral sean extrañas o lleguen a ser hostiles, hace que el ser sea malo, que sea ininteligible, que sea incierto; si no son solidarias, no sirven de nada"11.

Como se puede apreciar, en este texto la acción aparece trascendentalizada. Blondel se refiere a la acción, no como una manifestación del sujeto, sino como el elemento germinal que lo constituye todo, anterior a la separación que irá apareciendo con el desarrollo de la propia acción. Precisamente por ello, la investigación filosófica debe volver a esa unidad original, seguir su desarrollo y asistir al nacimiento de las formas, cada vez más complejas, de acción. Podría afirmarse que también en este

\footnotetext{
A 3 (VIII).

A $52(28)$.
} 
punto Blondel trataba de responder al extrinsecismo, aunque sería más exacto decir que se enfrentaba con la dificultad de la heteronomía.

Al situar el punto de partida de la investigación filosófica en la acción, Blondel ha privilegiado tres aspectos de la realidad: lo subjetivo (la acción hace referencia al sujeto que actúa, no a un objeto), la razón práctica que precede a la razón especulativa, y la inmanencia entendida no ontológicamente sino como método a seguir. Las cuestiones suscitadas por este triple componente de la acción así como la relación entre acción y conocimiento han sido suficientemente analizadas ${ }^{12}$. Aquí nos interesa sobre todo atender a la acción mediadora de la acción y a su culminación en la hipótesis de lo sobrenatural y, finalmente, del Mediador.

El motor del dinamismo de la acción es la necesidad de superar el desequilibrio interior de la voluntad. El hombre quiere necesariamente porque persigue la adecuación entre su querer profundo y los actos concretos de la voluntad, y esta adecuación nunca se realiza plenamente. Así aparece la necesidad intrínseca del dinamismo de la voluntad entendida como volonté voulante y volonté voulue. La "voluntad que quiere" es puro querer de todo lo posible, es ilimitada en sus aspiraciones, está dotada de un impulso cuya respuesta adecuada solo puede ser algo total, pleno y definitivo. La "voluntad querida", por su parte, es lo fáctico, el modo concreto, necesariamente limitado e imperfecto, en el que se ha concretado el empuje y la aspiración de la "voluntad que quiere". La volonté voulante se corresponde hasta cierto punto con la voluntas ut natura. Esta necesidad de la voluntad no alcanza a lo que se quiere. Lo que se quiere, los fines de la acción volitiva, son disociados por la volonté voulue $^{13}$, la cual es por ello expresión de la libertad, también en el caso de que lo querido no sea coherente con el querer profundo y necesario de la volonté voulante. A partir de la más elemental sensación y hasta las formas más altas de acción social "se despliega en nosotros un movimiento continuo del que es posible manifestar a la vez su encadenamiento riguroso y el carácter esencialmente voluntario" ${ }^{14}$. Este desequilibrio entre lo querido y lo hecho, entre lo posible y lo real es el alma del dinamismo de la acción.

12 Me he ocupado de estas cuestiones en mi obra De la razón a la fe. La aportación de M. Blondel a la teología (Eunsa, Pamplona, 1999) 52-84.

13 Cfr. Y. De Montcheuil, Mélanges Théologiques (Aubier, Paris, 1946) 249.

14 A $66(41)$. 
El desarrollo de la acción va dando lugar a síntesis superadoras del desequilibrio interior de la voluntad. A lo largo de los diferentes capítulos y etapas de La acción van surgiendo el conocimiento sensible, la ciencia, la operación voluntaria, la vida individual con su dimensión corporal, la acción social, las diversas formas de sociedad, la moral natural y un intento de religión natural. La misma acción subyace tanto a los conceptos metafísicos y a una moral independiente, como a las supersticiones en las que el hombre busca y no encuentra una respuesta plena al impulso inicial de su voluntad. Todo este proceso termina al final en un fracaso, porque el impulso de la voluntad que mueve a la acción no encuentra una respuesta adecuada en ninguna de estas realidades. La voluntad quiere más, sigue queriendo algo que todavía no tiene. En consecuencia, el hombre no puede limitar su destino a esos momentos de su desarrollo ${ }^{15}$. La pregunta por la finalidad de la vida humana sigue plenamente viva. La exigencia de la acción -que se ha hecho patente en la dialéctica- es infinita y no se contenta con nada provisional o parcial, es decir, con nada natural: ha de ser sobrenatural.

Al final, el querer de la voluntad, que no se ha amortiguado con ninguna realidad concreta, acaba siendo un querer de lo necesario, del "Único necesario"16. La respuesta que busca la libertad se muestra entonces como una realidad necesaria y absoluta que supera completamente el alcance de la voluntad. En relación con ese ideal, todo lo anterior es insuficiente. Pero, al mismo tiempo, el hombre se ve incapaz de alcanzar la respuesta que aparece en su horizonte, y solo la tendrá si le es dada. En este punto nos acercamos ya al término de la acción que aspira a Dios y a lo sobrenatural.

\section{ACCIÓN MEDIADORA}

Desde el principio, Blondel presenta la acción como síntesis y punto de encuentro de diversos elementos. Toda la filosofía de la acción es un intento de restablecer la unidad plena entre lo diverso -lo separado- que pertenece plenamente al hombre pero no se logra ver unido.

\footnotetext{
15 "Note rédigée par Maurice Blondel et destinée à être insérée dans les volumes de "L'Action" de 1893", en Études Blondeliennes 1 (1951) 78.

16 Tercer momento de la cuarta parte de A: pp. 387-404 (339.356)
} 
Blondel había estudiado en su tesis latina la cuestión del "vínculo sustancial" en Leibniz ${ }^{17}$. Dejando aparte la problemática concreta de esa teoría en el filósofo alemán ${ }^{18}$, parece claro que la idea del vinculum ejerció un poderoso atractivo sobre alguien como Blondel que quería proponer una solución vital y dinámica al problema de la separación de lo diverso en el hombre. Y así, Blondel se sirve del vinculum "para explicar el papel mediador de la acción, el ser de los fenómenos y la función realizadora del Verbo encarnado"19. Esta mediación significa, en Blondel, "el acto de reunir en una unidad transcendente el aspecto sensible y el aspecto ideal que todo compuesto presenta al análisis intelectual"20. Desde el punto de vista lógico, la síntesis parece posterior, como si fuera el resultado de los elementos que la componen. En realidad, sin embargo, es una realidad ontológica anterior de la que los elementos que en ella confluyen reciben una nueva forma.

La acción es "la mediadora entre el pensamiento y la vida, entre los fenómenos y el ser, entre los seres y el Ser" ${ }^{21}$. La eficacia mediadora de la acción se va desplegando progresivamente a través del dinamismo de la misma acción. En todas las nuevas expresiones de su desarrollo, la acción realiza su función mediadora en la medida en que es acto, es decir, en cuanto interviene el sujeto. "Toda verdad positiva exige la

17 La breve tesis latina que según el sistema vigente entonces en la universidad francesa presentó Blondel para acompañar a la tesis propiamente dicha (L'Action) tenía como título De vinculo substantiali et de substantia composita apud Leibnitium; publicada por CL. Troisfontaines, en Maurice Blondel. Le Lien substantiel et la substance composée d'après Leibniz. Texte latin (1893) (Nauwelaerts, Louvain, 1972). El mismo Troisfontaines ha publicado posteriormente la edición crítica en M. BLONDEL, Oeuvres complètes, I: 1893, Les deux thèses; texte établi et présenté par Claude Troisfontaines (PUF, Paris 1995).

18 Leibniz habla del vinculum substantiale al final de su vida, en la correspondencia con el P. Des Bosses (ed. Gerhardt, II, 286-521) para resolver el problema planteado por la transustanciación eucarística. El filósofo alemán habla ahí de una Unio o Vinculum que es un principio de unión por el que la sustancia compuesta es más que una suma de sustancias simples, y constituye una unidad original que no se puede descomponer. Cfr. J. Flamand, Liidée de médiation chez Maurice Blondel (Nauwelaerts, Louvain, 1969) 19-38. Frente a quienes pensaban que Leibniz no había mantenido personalmente la teoría del vinculum, Blondel defendía lo contrario: cfr. M. Blondel, Lettres Philosophiques (Aubier-Montaigne, Paris, 1961) 12.

19 Cl. Troisfontaines, "Introduction" a Maurice Blondel: Le lien substantial... 135.

20 Cl. Troisfontaines, "Introduction” a Maurice Blondel: Le lien substantial... 135.

21 J. Flamand, Lidée de mediation... 281-282. 
mediación de un acto, la presencia de un sujeto, sin el cual no habría verdad positiva" ${ }^{22}$. De ese modo va más allá de la separación entre lo objetivo y lo subjetivo, y se puede caminar hasta el "fondo de las cosas" que subyace a los fenómenos: "Las ciencias no nos dan ninguna luz sobre el fondo de las cosas; las ciencias exigen la mediación de un acto que es irreductible a ellas". El resultado de todo ello es paradójico: solo se puede hablar de objetividad en la medida en que es efectiva la mediación de un acto, de un sujeto.

La mediación de la acción muestra la solidez de los fenómenos a los que su dinamismo va dando lugar. Son siempre resultados parciales que llevan en sí la exigencia de superación o, mejor dicho, de autotrascendencia, pero son ciertos y permanentes. La acción mediadora realiza el encuentro de lo distinto y produce realidades nuevas que tampoco son autosuficientes porque responden solo parcialmente al impulso inicial y, en este sentido, son "insuficientes" y demandan ulteriores superaciones. Ello no es inconveniente para que constituyan fenómenos plenos, con capacidad, incluso, de atraer -a través de la opción mala- la fijación de sujetos que se conforman con ellos. Un ejemplo de ello sería lo que Blondel llama la "superstición de la ciencia" ${ }^{23}$ que es lo que caracteriza a quienes idealizan el conocimiento científico que se tiene de las cosas y se conforman con él, como si de esa manera hubieran alcanzado la realidad.

Blondel ha hablado de la dialéctica de la acción, pero se trata de una dialéctica muy alejada de la hegeliana ya que la mediación de la acción es, frente a la de Hegel, esencialmente afirmativa ${ }^{24}$. No hay en ella, como en el autor de La Ciencia de la Lógica, ningún tipo de Aufhebung que asuma aboliendo los extremos. Los progresos de la dialéctica blondeliana reconocen a la negación un papel provisional en la medida en que los nuevos pasos siempre conservan lo anterior, se enriquecen con ello y únicamente aceptan un exceso que lleva a negar que lo alcanzado sea lo definitivo. Como escribió Blondel, es una dialéctica no de la negación, sino de la "insuficiencia" y del "acrecentamiento" 25 . Podría afirmarse que

\footnotetext{
A 134 (101).

A $116(85)$.

24 Cfr. P. Henrici, Hegel und Blondel : eine Untersuchung über Form und Sinn der Dialektik in der "Phänomenologie des Geistes" und der ersten "Action" (Berchmanskolleg, Pullach, 1958).

25 M. Blondel, Lettres Philosophiques, 60.
} 
el efecto mediador de la acción alcanza en uno de sus polos un estadio superior que atrae e impulsa hacia nuevos fenómenos que responden mejor al dinamismo que mueve a la acción a adecuar sus logros con su deseo.

Con la mediación de la acción se va logrando cada vez de manera más plena la unidad entre pensar, querer y ser. Pero cuando se llega al límite de toda capacidad humana de desarrollo sigue pendiente el hallazgo de una respuesta plena al problema humano por lo que, si definitivamente no se logra, todo el proceso anterior amenaza con terminar en un fracaso. No hay al alcance del hombre un punto ulterior al que arribar, una orilla que alcanzar con la acción. Es entonces cuando surge la hipótesis de lo sobrenatural.

"El estudio completo del determinismo de la acción desemboca no en una realidad ni en una posibilidad, sino en una necesidad" ${ }^{26}$. Esta necesidad implícita en la acción, ulterior a todos los fenómenos, tiene como condición para su manifestación el conjunto de los fenómenos o, como dice Blondel, el "orden entero de la naturaleza", o "el orden natural" cuya insuficiencia y necesidad relativa "nos revela la necesidad absoluta de lo necesario" ${ }^{27}$. El contexto en que se sitúa esta reflexión es, en último término, soteriológico. El hombre llega a un límite en el que no se autosalva, sino que necesita ser salvado, y para ello debe ratificar mediante la opción esa necesidad que es necesidad de la "hipótesis necesaria", es decir, de lo sobrenatural. La necesidad no solo exige la opción sino que "esa misma necesidad es un don" 28 .

¿Qué realidad corresponde a lo sobrenatural tal como aparece en la filosofía blondeliana? Además de otras propiedades que le corresponden, es necesario insistir en su carácter hipotético: si existiera una realidad sobrenatural, todo el conjunto de los fenómenos tendría sentido. Un buen conocedor de la filosofía blondeliana, A. Valensin, discípulo e interlocutor epistolar de Blondel a lo largo de más cuarenta años, escribió el mismo año de la muerte del filósofo: "Si se debe producir una intervención sobrenatural, es libre de escoger soberanamente sus medios de acción. Pero no le está prohibido a la filosofía tratar de determinar a

\footnotetext{
A 134 (101).

A 392 (344); 365 (319).

A 436 (388); A 452 (401): “...imposible que no pensemos en la necesidad de una asistencia divina”.
} 
priori aquellos medios a partir de los cuales la naturaleza misma de las cosas establece una ley para el autor de la Naturaleza. Así es como la filosofía está, según Blondel, en la situación de descubrir en la religión hipotética, cuyas condiciones estudia, la necesidad de dogmas y de una práctica literal (...) Las preguntas son hipotéticas, las respuestas también son hipotéticas"29.

No es posible, en consecuencia, determinar el contenido de lo sobrenatural, sino solamente, y de forma hipotética, su forma. Blondel afirma inequívocamente que el contenido de la revelación supera absolutamente a la razón, y por tanto, que hay una distancia entre el contenido y la forma de la revelación.

El autor de la Lettre sur l'apologétique ha comparado lo sobrenatural a que llega la acción con unos "cuadros vacíos" 30 , dando a entender que ese sobrenatural es como una forma cuya existencia se plantea hipotéticamente a partir del dinamismo de la acción. Ahora bien, si la acción se pregunta por la existencia de una "forma" sobrenatural, es porque el proceso que sigue es también "formal"; no va acompañado de la afirmación ontológica que le podría corresponder. El desarrollo de la acción se presenta entonces como una fenomenología, y no como una ontología. Lo que en ese desarrollo aparece son fenómenos, ninguno de los cuales puede reivindicar para sí mismo una consistencia ontológica. La realidad de la revelación siempre va más allá: "La revelación, para ser lo que tiene que ser si existe, debe superar a la razón tanto en su principio como en su objeto como en su fin. Ningún esfuerzo del hombre puramente hombre logrará penetrar su esencia" ${ }^{31}$.

A partir, pues, de una consideración fenomenológica de la acción, no solo es posible sino incluso necesario plantearse la necesidad de lo sobrenatural, aunque sea simplemente como "cuadros vacíos". Una vez, sin embargo, que se trata de lo sobrenatural, irrumpe casi al mismo tiempo la cuestión ontológica. Blondel considera que se puede hablar de ontología, de condiciones suficientes para afirmar la realidad y el ser solamente

29 A. Valensin, "Maurice Blondel et la dialectique de l'action”, en Études 263 (1949) 159

30 M. BlOndel, Lettre sur les exigences de la pensée contemporaine en matière d'apologétique et sur la mèthode de la philosophie dans l'étude du problème religieu (1896): M. Blondel, Oeuvres complètes, II, 130

$31 \quad$ A 458 (407) 
después de haber expuesto su reflexión sobre el Mediador, sobre Cristo. La fundamentación cristológica de la realidad es el momento cumbre de la filosofía de la acción.

Antes, sin embargo, de ocuparnos del Mediador, conviene examinar una especificación de lo sobrenatural que el filósofo apunta en La acción pero que ha desarrollado en escritos posteriores. Se trata de lo que Blondel designa como "sobrenatural anónimo".

\section{SOBRENATURAL ANÓNIMO}

La expresión "sobrenatural anónimo" le sirve a Blondel para designar las condiciones a priori de la hipótesis de lo sobrenatural. Significa que hay en el sujeto mucho de preparación, de anticipación, de planteamiento hipotético de lo sobrenatural. Lo sobrenatural no viene al hombre -ni el hombre reacciona ante lo sobrenatural- como algo que viene totalmente de fuera, como una especie de meteorito. Ya en La acción se utiliza el término "anónimo" para expresar esta idea. Pero es sobre todo en escritos publicados con el prète-nom de F. Mallet, donde Blondel ha dado un paso al frente al incorporar a su caracterización de lo sobrenatural el calificativo de "anónimo"32.

El término "anónimo" aparece en L'Action cinco veces, aunque, con excepción de un caso, en contextos que nada tienen que ver con lo sobrenatural ${ }^{33}$. Esa única excepción se encuentra en las páginas dedicadas a tratar del Único Necesario, en las que el calificativo "anónimo" incor-

32 Cfr. F. Mallet (= M. Blondel) "L'oeuvre du Cardinal Dechamps et les progrès récents de l'apologétique", en Annales de Philosophie Chrétienne 153 (1907) 561591. El canónigo Mallet firmó entre 1905 y 1913 seis artículos que la Bibliographie analytique et critique editada por $\mathrm{R}$. Virgoulay y $\mathrm{Cl}$. Troisfontaines, considera que tienen realmente como autor a Blondel. Como he expuesto en otro lugar ("Le surnaturel anonyme et la foi. Les articles de Blondel signés Mallet", en Annales Theologici 16 (2002) 355-379) no parece lógico reducir la autoría de F. Mallet a la pura firma; sin duda aportó algo suyo, aunque la parte sustancial fuera del filósofo. Más tarde, Blondel recogió una parte de esos seis artículos y los publicó en Le problème de la philosophie catolique (Bloud\&Gay, Paris 1932). La terminología utilizada es la siguiente: "bypothèse d'un surnaturel subjectif et anonyme"; "présence anonyme et spontanée mais indispensable du surnaturel inmanent"; "fait intime, même anonyme"; "apologétique anonyme".

33 A 202 (165); 278 (236); 310 (266); 330 (286); 402 (353). En este último texto, situado en las páginas dedicadas a "L'unique nécessaire" se trata de la presencia de Dios en el hombre. 
pora un significado próximo a lo sobrenatural. A la luz, precisamente, del "sobrenatural anónimo" tal como lo desarrollará más tarde, ese texto cobra un sentido especial.

En esas páginas, Blondel se refiere a la eficacia de la presencia de Dios en todo hombre, eficacia que, a su vez, tiene que ver con el pensamiento que el hombre tiene sobre Dios y, por tanto se relaciona con el argumento ontológico. Escribe Blondel: "La verdad de esta presencia tiene una eficacia absoluta, sea cual sea la forma en que se manifieste a la conciencia, clara o confusa, consentida o rechazada, manifiesta o anónima" ${ }^{34}$. Como se ve no hay una referencia directa a lo sobrenatural, y sin embargo es claro que la "présence anonyme de Dieu" plantea de lleno no la mera presencia metafísica propia de la relación creatural del hombre con Dios, sino una acción de Dios en todo hombre más allá de la mera creación.

Lo "anónimo" es necesariamente una realidad interior, oculta. Al utilizarla en su explicación, Blondel/Mallet trata lógicamente de encontrar en el "hecho interior" ${ }^{35}$, que se da en toda persona, la preparación, el movimiento o impulso que conduce a la acogida del "hecho exterior", al hecho "sobrenatural exterior e histórico" ${ }^{36}$. Para ello, de todos modos, es preciso que opere el principio de homogeneidad: para que el impulso de la vida se abra y acoja el hecho exterior es necesario que la realidad que en este se manifiesta se presente como la plenitud y el cumplimiento de algo que ya está operando en el hombre. La realidad inmanente y anónimamente consciente de lo sobrenatural es un hecho de conciencia que es perceptible no en sí mismo, ut est, sino en sus efectos internos, ut agit, de manera que así se prepara "la voz que lo llama, la luz que lo discierne, el amor que abraza" al don que viene de fuera de nosotros ${ }^{37}$. La realidad inmanente y anónima de lo sobrenatural no es por tanto objeto de experiencia directa ni tampoco de una experiencia trascendental, porque se relaciona en primer lugar con los efectos internos de una praxis o acción. En último término se trata de las disposiciones morales que no son

A 401-402 (353). El subrayado es nuestro

35 F. Mallet (= M. Blondel), "L'œuvre du Cardinal Dechamps et la méthode de l'apologétique", en Annales de Philosophie Chrétienne 151 (1905) 68-91.

36 F. Mallet (= M. Blondel), "L'œuvre du Cardinal Dechamps et la méthode de l'apologétique", 76-77.

37 F. Mallet (= M. Blondel), "L'oeuvre du Cardinal Dechamps et les progrès récents de l'apologétique", 581-582. 
simplemente preparatorias y extrínsecas, sino sobre todo "constitutivas y permanentes" 38 .

Lo sobrenatural anónimo se relaciona en primer lugar con la práctica, a partir de la cual se adquiere el conocimiento implícito del que ha hablado repetidamente el filósofo de Aix. En este conocimiento los actos van por delante, y las ideas derivan "de tendencias infusas y de experiencias prácticas" ${ }^{39}$. Aquí encuentra su lugar la distinción blondeliana también entre el conocimiento y la realidad. A la realidad se accede de modo pleno sobre todo por la práctica, de forma que ser es sobre todo actuar, y solamente algunos aspectos parciales de este ser-actuar son los que alcanza el conocimiento (explícito).

El carácter anónimo de lo sobrenatural significa precisamente al hecho de que cae dentro del campo del conocimiento implícito, aquel que está impregnando la forma concreta de actuar y de vivir. Lo sobrenatural anónimo es, por tanto, de carácter práctico. Consiste en el conjunto de opciones que corroboran la apertura y el impulso de la existencia hacia su sentido pleno en el encuentro con lo sobrenatural explícito. "Lo sobrenatural subjetivo y anónimo que es, ante todo, un hecho psicológico... es la condición de todo discernimiento y de toda asimilación del hecho exterior y de la noción objetiva y explícita de lo sobrenatural" ${ }^{\prime 4}$. De este modo, Blondel quiere establecer una auténtica preparación a la fe. Recoge la realidad de que en las personas hay acciones que se mueven en la dirección de la apertura hacia Dios, conocido al menos como Verdad y como Bien a realizar, aunque no se conozca su nombre. Esas acciones se dirigen objetivamente hacia lo sobrenatural, y ese destino es el que las constituye en auténtica preparación para el don de la fe. De ese modo se evita un dualismo excesivo entre la situación del hombre previa a la fe y la del mismo hombre que ya cree. Se trata de un sobrenatural

38 F. Mallet (= M. Blondel), "L'oeuvre du Cardinal Dechamps et les progrès récents de l'apologétique", 573.

39 F. Mallet (= M. Blondel), "L'oeuvre du Cardinal Dechamps et les progrès récents de l'apologétique", 583. El texto continúa: "L'étude de ces rélations intestines ouvre un domaine immense à la psychologie religieuse; car c'est le lieu normal d'échange entre la théologie spéculative et la théologie mystique et ascetique: tout ce qu'on pourra explorer de ce domaine contribuera au profit de l'une et de l'autre".

40 F. Mallet (= M. BlOndel), "L'oeuvre du Cardinal Dechamps et les progrès récents de l'apologétique", 584. 
inmanente, subjetivo. Su origen, como recuerda el filósofo, no es ex natura, pero su realidad se da in natura. Se trata realmente de una gracia.

Por relación con lo "sobrenatural anónimo" se puede trazar una "apologética anónima”. Blondel es consciente de que hay que precisar este término. En realidad, la apologética anónima es la misma filosofía de la acción en la medida en que establece la primacía de la realidad espiritual, del ser sobre el conocer. En este contexto, la filosofía de la acción es una apologética anónima en cuanto sitúa el punto de partida de toda investigación en la acción, que tiene como una concreción suya fundamental el conocimiento ${ }^{41}$.

El objeto sobrenatural y la preparación del sujeto (el "hecho interior") son ambos necesarios para llegar al acto sobrenatural de fe, pero en el segundo ya opera lo sobrenatural aunque anónimamente ${ }^{42}$. El objeto sobrenatural que existe fuera de nosotros es la condición del conocimiento que tenemos de él por revelación, y al mismo tiempo es "la fuente de la gracia que nos permite adherirnos a la realidad redentora y, a través de ella, a la enseñanza revelada” ${ }^{43}$.

41 F. Mallet (= M. Blondel), "L'oeuvre du Cardinal Dechamps et les progrès récents de l'apologétique", 574.

42 A propósito de la posible afinidad entre el pensamiento de Blondel y el de K. Rahner que algunos propugnan, puede ser de interés una breve referencia al uso del término "anónimo" en uno y otro autor. Rahner lo ha utilizado especialmente en su escrito "Los cristianos anónimos" (en Escritos de Teología VI, [Taurus, Madrid, 1969] 535-544). Ambos autores comparten la necesidad de superar el extrinsecismo, es decir, una ausencia de relación previa al encuentro entre el hombre y la realidad sobrenatural. Pero hay grandes diferencias. Lo sobrenatural anónimo de que habla Blondel se da en el hecho interior y va unido a un "fait de conscience", un "fait psychologique", perceptible ut agit, penetrado de la tensión que le empuja hacia el hecho exterior, sin el cual no tendría sentido. Es la experiencia del vacío real en nosotros, que no nos permite encerrarnos en nuestra naturaleza. El anónimo rahneriano, en cambio, es atemático y goza de una cierta autonomía - no completa, sin embargo- en relación con el dato externo o histórico. Pero la mayor diferencia entre el anónimo de Blondel y el de Rahner se da en el método seguido para acceder a lo sobrenatural. Rahner se ha servido del método trascendental, buscando las condiciones a priori de la existencia humana. Blondel, en cambio, ha seguido su método de inmanencia atento a lo que sucede, en lo que está más cercano al método fenomenológico. Como consecuencia, lo implícito -más que atemático- tiende a explicitarse mediante la historia, la praxis y la reflexión; en Rahner, en cambio, hay una tendencia a resolver lo temático en atemático, y lo histórico en trascendental. Cfr. C. IzQuierdo, "Le surnaturel anonyme et la foi", 367-370.

43 C. IZQUIERDO, "Le surnaturel anonyme et la foi", 586-597. 


\section{El MEDIADOR}

A pesar de la insistencia blondeliana en la mediación de la acción, Blondel habla del Mediador más que de la mediación para dar a entender que no hay una solidez previa de las cosas sino que deben participar de la consistencia del Mediador: "el Mediador es la realidad por excelencia" ${ }^{44}$.

Hasta ahora la mediación de la acción se ha mantenido en el ámbito de los fenómenos parciales, pero es necesario plantear la pregunta por el modo como puede darse la mediación entre todo lo que existe. La cuestión de fondo en este punto conecta con el problema ontológico. Cuando se trata de la síntesis que el sujeto va realizando mediante la acción en los fenómenos, queda pendiente que estos reciban un fundamento final. "La realidad del fenómeno, y con ella el sistema total y el conjunto mismo de los espíritus, se desvanecería sin este doble vínculo de lo relativo con lo absoluto y de lo absoluto con lo relativo" ${ }^{45}$.

Para alcanzar la consistencia que la realidad otorga a los fenómenos producidos por la actividad del sujeto y que expresan la acción, estos tienen que ser recibidos, acogidos y como reflejados por una pasividad que, al hacerlo, les da la objetividad que los hace ser más allá de la inmanencia: "Ser objetivo significa ser producido y padecido por un sujeto" ${ }^{46}$. Y en este mismo contexto, Blondel escribe: "Siendo pasiva en el fondo, es preciso que la naturaleza, para ser, tenga una verdadera acción, y que dicha acción encuentre su perfecta consistencia en la pasión voluntaria de un ser capaz de conferir a su conocimiento un carácter de absoluto". Tras esta afirmación está el convencimiento de que la naturaleza -su representación- no puede ser puramente percibida, porque entonces no trascendería al hecho de ser mi representación y no podría afirmarse su propia subsistencia. Debe, en consecuencia, producir una cierta acción y ser no solo percibida sino condición misma de la percepción para lo cual es preciso que exista una pasividad correspondiente en quien percibe ${ }^{47}$. Estamos ya ante la necesidad de un mediador.

\footnotetext{
44 P. Favraux, Une philosophie du médiateur, 237.

45 A $514(460)$.

46 A 509 (456): "Être objectif, c'est donc être produit et subi par un sujet; car avoir une action réelle sur un être reel, c'est être reel".

47 A 508-509 (455-456).
} 
¿Podría ser el hombre, vinculado a lo sobrenatural, este mediador? Inicialmente, la respuesta positiva parece posible. "El hombre -escribe Blondel- es un «microcosmos», summa mundi et compendium, el resumen de todas las experiencias, de todas las invenciones y de todas las ingeniosidades de la naturaleza, extracto y producto original de todo el conjunto. El universo concentra en él sus rayos" ${ }^{38}$. Con más claridad todavía lo afirma el filósofo al comienzo del último capítulo de $\mathrm{La}$ acción, que lleva por título "El vínculo del conocimiento y de la acción en el ser" ${ }^{49}$. Allí leemos: "al fundar absolutamente la realidad universal de la cual se ha nutrido la acción, es cuando el hombre acaba su tarea, esa tarea que consiste en ser el vínculo real de las cosas y en conferirles todo lo que implican a nivel de ser" ${ }^{\circ 0}$. Un poco más adelante, sin embargo, la afirmación se vuelve hipotética: "Quizá el hombre, destinado a recibir en sí la vida divina, hubiera podido desempeñar este papel de vínculo universal y ser suficiente para esta mediación creadora, ya que esta inmanencia de Dios en nosotros sería como el centro magnético que vinculara todas las cosas, como un haz de agujas invisiblemente unidas por un potente imán" ${ }^{51}$.

La mediación universal pasa, ciertamente, por el hombre pero no basta el hombre aunque esté promovido a lo sobrenatural. En efecto, el hombre forma parte de lo que debe ser fundado: "su pensamiento y su acción son simples fenómenos que deben ser fundados como todo lo demás" 52 . Solo hay un hombre que pueda ser el vínculo universal de todo, el único Mediador, y es el Hombre Dios, el Verbo encarnado. El texto clave de La acción es el siguiente:

"Pero para que, a pesar de todo, la mediación fuera total, permanente, voluntaria, tal, en suma, que pudiera asegurar la realidad de todo lo que indudablemente podría no ser, de aquello que, siendo como es, exige un testigo divino, quizá fuera necesario un Mediador que se

\section{A 127 (95).}

49 Sobre el último capítulo de L'Action, cfr H. Boulllard, "Le denier chapitre de L'Action", en Archives de Philosophie 24 (1961) 29-113; X. Tilliette, "Le panchristisme dans L'Action et les premiers écrits, en R. Virgoulay (dir.), Le Christ de Maurice Blondel (Desclée, Paris, 2003) 44-50. Tilliette se refiere a "les pages denses et parfois obscures, voire, abstruses", al "parcours sinueux, d'un raisonnement qui sollicite une attention soutenue et quelquefois deconcertée" (p. 45).

50 A 477 (424).

51 A 514 (461).

52 P. Favraux, Une philosophie du Médiateur, 230. 
hiciese paciente respecto de esta realidad integral y que fuera como el Amén del universo, "testis verus et fidelis qui est principium creaturae Dei”. Quizá fuera necesario que, hecho carne él mismo, constituyera, mediante una pasión al mismo tiempo necesaria y voluntaria, la realidad de lo que es determinismo aparente de la naturaleza y conocimiento forzado de los fenómenos objetivos, la realidad de las deficiencias voluntarias y del conocimiento privativo que es su sanción, la realidad de la acción religiosa y del destino sublime reservado al hombre plenamente consecuente con su propio querer" 53 .

Se trata de la "hipótesis del Mediador" que aparece nombrada después de un "quizá fuera necesario un Mediador...". El texto precedente contiene una síntesis del pensamiento blondeliano sobre el acceso a Cristo. Como ya se ha apuntado anteriormente, toda actividad exige una correlativa pasividad en la que aquella pueda ser recibida. Así, por ejemplo, los fenómenos existen por la actividad de la razón, pero al mismo tiempo existen porque los sentidos se hacen pasivos de su acción. Es necesaria una pasividad que acoja la actividad para que esos fenómenos existan, porque de otro modo la pura actividad, sin la réplica de la pasividad que la recibe, carecería de todo significado.

Si el principio de que toda actividad implica una correlativa pasividad, y viceversa, se lleva a la realidad natural, hay que afirmar que la naturaleza no puede ser entendida como puramente pasiva, como algo que únicamente puede ser percibido, porque entonces se convertiría en pura representación subjetiva, sin que pudiera afirmarse su propia subsistencia. Por eso, para que se puedan afirmar, no solo sus fenómenos sino también su realidad, la naturaleza debe producir una cierta acción y ser, no solo percibida, sino condición misma de la percepción. La naturaleza será algo más que puros fenómenos y gozará de realidad si, además de que esos fenómenos sean percibidos, produce una cierta acción que es recibida por alguien que, en ese preciso sentido, es pasivo de aquella acción. "Para que las cosas que son percibidas sean percibidas tales como son, no basta con un conocimiento perceptivo o pasivo, sino que hace falta un conocimiento racional y productivo. Tampoco basta con un conocimiento productivo o racional, sino que hace falta un conocimiento perceptivo o pasivo. La realidad de las cosas consiste en ser mediadoras entre este doble aspecto" ${ }^{54}$. En resumen, la totalidad de las cosas no es

53 A 514 (461).

54 A $512(459)$. 
puramente pasiva, sino que debe actuar, ratificando con su actividad la relación que las pone en el ser, sin que por ello esa relación deje de ser una relación de creación. Si no se diera esa actividad, su consistencia estaría comprometida.

Este camino termina en la necesidad hipotética del Emmanuel, de que el Absoluto, al encarnarse, haga al Creador voluntariamente pasivo de lo creado. El Mediador ratifica, no con una pasividad necesaria, sino con su pasión voluntaria, la acción de la naturaleza a la que de este modo da la mayor la consistencia posible. Por eso Cristo es el Amen del universo, la ratificación de la realidad de las cosas". "(El Mediador) es la medida de todas las cosas" ${ }^{\prime 5}$. Todo se apoya en él, y solamente en él son conocidas las cosas en su auténtica realidad. Él es "el Realizador universal, fuente y vínculo de todo ser" ${ }^{\text {" }}$. Esta afirmación es de gran calado en cuanto permite que los fenómenos -el "fenomenismo" de las cienciasaboque a la realidad, cerrando así el camino a que sea el positivismo el que tenga la última palabra.

El esquema explicativo parece claro: la totalidad de la experiencia pide un ser capaz de conocerla y de ratificar ese conocimiento para que las cosas no sean puramente pasivas y por tanto privadas de consistencia ontológica. Cuando las cosas ratifican con su actividad la relación que las pone en el ser, la relación que establecen sigue siendo una relación de creación. De ese modo, el Absoluto -con su pasión voluntaria- acoge la "reacción" de la creación, de la que Él es el origen. La encarnación se hace entonces inteligible, ya que Cristo es Dios creador que se hace voluntariamente pasivo de la criatura, dándole así la mayor consistencia posible. Cristo es el Vinculum, el Mediador, la clave de bóveda del universo.

El acceso a la realidad del Mediador no es posible con la sola inteligencia. Lo mismo que el problema del ser y del conocimiento, ese acceso concierne a todo el hombre, inteligencia y voluntad, que deben realizar una opción que, a su vez, se convierte en parte integrante de la búsqueda del ser. Blondel, que había escrito "el sacrificio es la solución del proble-

Cfr. C. IzQuierdo, Blondel y la crisis modernista (Eunsa, Pamplona, 1990) 288-295 A 515 (461).

57 M. BlOndel, Lettre sur les exigences de la pensée contemporaine en matière d'apologétique, 168. 
ma metafísico por el método experimental"58; o "la mortificación es, por tanto, la verdadera experimentación metafísica, la que se apoya sobre el ser mismo" 59 , señala que la opción buena, a través de la "práctica mortificante" se convierte en verdadero amor. De este modo, la realidad por excelencia que es el Mediador es primero amado y después conocido ${ }^{60}$.

La explicación última del mediador blondeliano es que en él se concentra la respuesta a la pregunta inicial de la acción por el sentido de la vida humana. Para Blondel, el sentido de la vida aparece como el problema radical de la separación, como ya hemos visto anteriormente, entre conocer, querer o actuar, y ser. Pero más allá de esta dimensión profunda, el hombre -también el contemporáneo- percibe el problema del sentido a partir de la soledad radical de la existencia y de la insignificancia de su vida en el conjunto del cosmos. Perdido ante lo infinito, sin importancia ante lo eterno, pregunta sin respuesta posible sobre sí mismo, el hombre que intenta responder con su acción a la pregunta constante por su ser, acaba desesperado porque no ve el modo de superar su finitud, el tiempo, la niebla que acompaña a su mente. La tentación que surge es, inevitablemente, el nihilismo y la desesperación porque la respuesta a la pregunta por el sentido de la vida es negativa.

Pero es ahí, precisamente, donde se plantea la respuesta que no puede venir del hombre. La mediación que a lo largo de la historia ha sido objeto de reflexión porque viene a responder a problemas ancestrales de la razón, se plantea ahora en el nivel más alto: entre Dios y el hombre. Algo de esto había tenido reflejo en la filosofía y en la mitología griegas con el demiurgo, Eros o el robo del fuego divino por Prometeo. Ahora, la particularidad del desarrollo de la filosofía muestra con toda claridad que el hombre solo puede poner su deseo mientras que a Dios mismo le toca salir de su misterio y cruzar al tiempo, al cosmos, al hombre y dar sentido a todo haciéndose él mismo tiempo, criatura, hombre; mediador en una palabra.

La acción y la pasión del Mediador trazan el arco en el que todo extrinsecismo queda superado porque en el encuentro que en él se realiza, se anulan las oposiciones, se traza la continuidad entre los diversos estados sin que, al mismo tiempo, se naturalicen los dones de Dios. Si

\footnotetext{
58 A 495 (442).

59 A 431 (383).

60 Cfr A 475 (423).
} 
se mira al hombre desde el Mediador, si se considera el cosmos igualmente desde Cristo mediador, tanto la realidad del hombre como la del cosmos aparecen con una densidad de significado y con un futuro que resultan inimaginables para una consideración autónoma de las mismas realidades. Mirar al hombre y al cosmos desde Cristo mediador en quien ambos ya se encuentran en la unidad con el Verbo, es el único modo de hacer justicia a la realidad profunda que contienen y son; sin Cristo, lo que conocemos es un hombre fraccionado y enigmático, y un cosmos sin verdadera razón de ser y, por tanto, igualmente incomprensible.

\section{CONCLUSIÓN}

Con la hipótesis del Mediador se ha planteado si Blondel propone una cristología filosófica estricta. Al presentarlo como el fundamento de la realidad creada parece que implica a la encarnación como la condición necesaria de la consistencia ontológica de la naturaleza.

Es innegable que la teoría de Blondel guarda similitudes con la corriente cristológica franciscana que relaciona la creación y la encarnación. De ahí, sin embargo, no se puede concluir que nos encontremos ante una cristología filosófica. El filósofo ha utilizado un término propio, el pancristismo, con el cual quiere expresar "la amplitud universal de la función de Cristo, no porque todo sea Cristo, sino porque en Cristo todo recibe consistencia definitiva" ${ }^{31}$. La presentación blondeliana del Mediador se puede considerar como una glosa filosófica de lo que afirman los himnos cristológicos de las cartas paulinas (Col 1, 15-17, especialmente; también Ef 1,4; Fil 2,6-9). Decimos que es glosa filosófica porque está implicada la filosofía en el sentido amplio en que la entendía Blondel. En ella, es posible plantearse la legitimidad de considerar el valor filosófico de los dogmas cristianos. Su respuesta es que "es legítimo considerar estos dogmas, no ciertamente en primer lugar como revelados, sino como reveladores" ${ }^{62}$. Es legítimo aceptarlos a título de hipótesis, confrontándolos con las exigencias profundas de la voluntad

${ }_{61}$ R. VirgoulaY, "La christologie philosophique de Maurice Blondel", en D. FolsCHEID (ed.), Maurice Blondel. Une dramatique de la modernité (Editions Universitaires, Paris, 1990) 204. También cfr, R. Virgoulay, Philosophie et Théologie chez Maurice Blondel (Cerf, Paris, 2002) especialmente el capítulo VI: "L'action, le Vinculum, le médiateur".

62 A 441 (391). 
y "descubriendo en ellos, si es que está en ellos, la imagen de nuestras necesidades reales y la respuesta esperada" ${ }^{63}$. La relación entre la creación y la encarnación en el sentido de que aquella está en función con esta última, es decir, que la encarnación es el supremo fin de la creación, es para Blondel "un dogma implícito, aún no proclamado" ${ }^{64}$.

Para terminar, debemos observar que el extrinsecismo en teología no desapareció con la crítica blondeliana. Autores recientes siguen considerando que su superación es una tarea permanente del trabajo teológico ${ }^{65}$. Pero el planteamiento del filósofo de Aix conserva una eficacia innegable. El Mediador al que llegaba ya en sus primeras obras como condición de la consistencia de lo que existe no es distinto del Mediador de la cristología contemporánea. Asociar la perspectiva del filósofo con la de los Padres y teólogos contribuye a una consideración del misterio cristiano en el que naturaleza y don se dan en un permanente movimiento de ascenso y descenso: "Hasta el impulso de búsqueda que nos lleva a Dios tiene que ser, en su principio, un don. Sin esta mediación indispensable no somos ni podemos nada"66.

\footnotetext{
63 A 441 (391).

64 X. Tilliette, "Le panchristisme en L'Action", 44.

65 L. Melina, Plenitud del obrar cristiano (Palabra, Madrid, 2001) 181; F. Berríos, "Von Balthasar y Rahner: Vigencia de una interlocución teológica", en Teología y Vida 50 (2009) 91.

66 A 449-450 (398).
} 


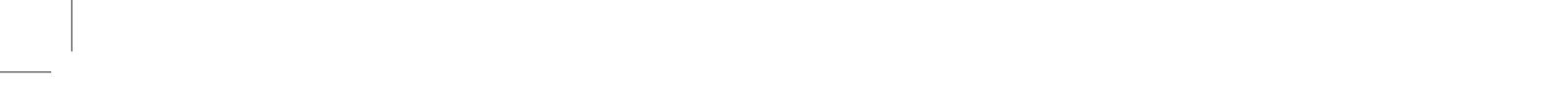

